\title{
LINGUISTIC AND GRAMMATICAL TERMS IN ENGLISH AND PORTUGUESE
}

\section{ENGLISH}

\section{General Terms}

Portuguese

English

Spanish

Latin

Lusophone

Romance language

abbreviation

antecedent

category

clause

ending

expression

form

language

linguistics // linguistic

marker

phrase

placement

radical / root / stem

semantics // semantic

sentence

stress // stressed poststressed prestressed

syllable

symbol

term // terminology

transcription

variant

word

\section{PORTUGUESE}

\section{Os Termos Gerais}

(o) português

(o) inglês

(o) espanhol

o latim / latino

(o) lusófono

a língua românica / romance

a abreviatura / a abreviação

(o) antecedente

a categoria

a oração

a terminação

a expressão

a forma

a língua

a linguística // linguístico ${ }^{1}$

o marcador

a frase / a locução / a expressão

a colocação

o radical / a raiz

a semântica // semântico

a frase

a acentuação tônica // tônico pós-tônico

pré-tônico

a sílaba

o simbolo

o termo // a terminologia

a transcrição

(a) variante

a palavra

${ }^{1}$ Portuguese no longer uses a dieresis (“) over the $u$ of $g u$ to transcribe $\left[\mathrm{g}^{\mathrm{u}}\right]$. 


\section{ENGLISH}

\section{Sound System}

aspirated

consonant

dental

diphthong

hiatus

intervocalic

nasal

oral

phonetics // phonetic

semivowel

phonetic symbol

sound

voiced

voiceless

vowel

\section{Writing System}

accentuation

alphabet

diacritical $(=$ accent $)$ mark $^{1}$

homograph

homonym

letter (orth.)

capital / uppercase letter

small / lowercase letter

orthography // orthographic orthographic reform

punctuation punctuation mark ${ }^{2}$

typographic symbol ${ }^{2}$

word division

word stressed on:

second-to-last syllable (proparoxytone)

next-to-last syllable (paroxytone)

last syllable

\section{PORTUGUESE}

\section{Os Sons}

aspirado

a consoante

dental

o ditongo

$o$ hiato

intervocálico

nasal

oral

a fonética // fonético

a semivogal

o símbolo fonético

o som

sonoro

surdo

a vogal

\section{A Ortografia}

a acentuação gráfica

o alfabeto / o abecedário

o acento gráfico ${ }^{1}$

o homógrafo

o homônimo

a letra

$$
\text { a letra maiúscula }
$$

a letra minúscula

a ortografia // ortográfico

a reforma ortográfica

a pontuação

o sinal de pontuação ${ }^{2}$

o símbolo tipográfico ${ }^{2}$

a divisão de palavras

a palavra:

$\begin{aligned} & \text { proparoxitona / esdrúxula } \\ & \text { paroxitona } \\ & \text { oxitona }\end{aligned}$
/ grave
aguda

${ }^{1}$ See p. 22 for names of specific diacritical marks.

${ }^{2}$ See p. 21 for names of specific punctuation marks and typographic symbols. 


\section{ENGLISH}

\section{Cognates}

derived word

prefix

radical / root / stem

root word

suffix

\section{Grammar}

adjective:

demonstrative

possessive

adverb

adverb phrase

article (definite / indefinite)

augmentative

clause:

$$
\begin{aligned}
& \text { main } \\
& \text { subordinate (dependent): } \\
& \text { noun } \\
& \text { adjective: } \\
& \\
& \\
& \\
& \\
& \\
& \text { restrictive } \\
& \text { nonrestrictive }
\end{aligned}
$$
adverb:

conditional

comparative

comparison of:

equality

superiority / inferiority

conjunction

contraction

diminutive

feminine

form of address

gender

grammatical

masculine

nominalization

noun

predicate noun

number (gram. / math.)

numeral

\section{PORTUGUESE}

\section{Os Cognatos / Cognados}

o derivado / a palavra derivada

o prefixo

o radical / a raiz

a palavra-raiz

o sufixo

\section{A Gramática}

$o$ adjetivo:

$o$ advérbio

demonstrativo

possessivo

a locução adverbial

o artigo (definido / indefinido)

(o) aumentativo

a oração:

$$
\begin{gathered}
\text { principal } \quad \text { (independente) } \\
\text { subordinada (dependente): } \\
\text { substantiva } \\
\text { adjetiva: } \\
\text { restritiva } \\
\text { explicativa } \\
\text { adverbial: }
\end{gathered}
$$

(o) comparativo

a comparação de:

igualdade

superioridade / inferioridade

a conjunção

a contração

(o) diminutivo

feminino

a forma de tratamento

o gênero

gramatical

masculino

a nominalização

o substantivo / o nome

o número

o substantivo predicativo

o numeral 


\section{ENGLISH}

object:

direct / indirect

prepositional

reflexive

person

plural

preposition // prepositional

prepositional phrase

pronoun:

demonstrative

object

personal

possessive

prepositional

reflexive

subject

sentence:

conditional

singular

subject

superlative:

absolute ("synthetic" / "analytic")

relative

word:

affirmative / negative

indefinite

interrogative

relative

\section{Verbs}

conjugation

expression:

impersonal

of time

"progressive"

tense (simple / compound)

verb:

impersonal

reflexive

transitive / ditransitive / intransitive

verb group

voice (active / passive)
PORTUGUESE

o objeto:

direto / indireto

preposicional

reflexivo

a pessoa

plural

a preposição // preposicional

a frase / a locução preposicional

o pronome:

demonstrativo

oblíquo

pessoal

possessivo

preposicional

reflexivo

re(c)to

a frase:

condicional

singular

o sujeito

(o) superlativo:

absoluto (sintético / analítico)

relativo

a palavra:

afirmativa / negativa

indefinida

interrogativa

relativa

\section{Os Verbos}

a conjugação

a expressão:

impessoal

de tempo

progressivo / contínuo

o tempo (simples / composto)

o verbo:

impessoal

reflexivo

transitivo / ditransitivo / intransitivo

a locução verbal

a voz (ativa / passiva) 


\section{ENGLISH}

\section{Verb Moods and Tenses}

$\operatorname{mood}($ gram.)

imperative

indicative

present

present perfect

preterite (preterite perfect)

imperfect (preterite imperfect)

simple past perfect (pluperfect)

compound past perfect (pluperfect)

future

future perfect

conditional

conditional perfect

subjunctive

present

present perfect

past (imperfect)

past perfect (pluperfect)

future

future perfect

\section{Verb Forms}

verbal

infinitive (impersonal / personal)

past participle

present participle

gerund

\section{PORTUGUESE}

Os Modos e Tempos Verbais

\section{o modo}

o imperativo

$o$ indicativo

o presente

o pretérito perfeito composto

o pretérito perfeito simples

o pretérito imperfeito

o pretérito mais-que-perfeito simples

o pretérito mais-que-perfeito composto

o futuro do presente simples

o futuro do presente composto

BP: o futuro do pretérito simples

EP: o condicional simples

BP: o futuro do pretérito composto

EP: o condicional composto

BP: o subjuntivo

EP: o conjuntivo

o presente

o pretérito perfeito composto

o pretérito imperfeito

o pretérito mais-que-perfeito composto

o futuro simples

o futuro composto

\section{As Formas Verbais}

a forma nominal do verbo

o infinitivo (impessoal / pessoal)

o particípio passado

o particípio presente

o gerúndio 